\title{
The effect of pre- and postnatal exposure to a mixture of daidzein and genistein on the reproductive system of male rats
}

\author{
Mariola Marchlewicz, A, Dagmara Szypulska-Koziarska², B, Irena Baranowska-Bosiacka ${ }^{3, C}$, Ewa Duchnik ${ }^{4, D}$, \\ Barbara Wiszniewska2, E, Joanna Kruk, ${ }^{5} \bowtie$ \\ ${ }^{1}$ Pomeranian Medical University in Szczecin, Department of Aesthetic Dermatology, Powstańców Wlkp. 72, 70-111 Szczecin, Poland \\ ${ }^{2}$ Pomeranian Medical University in Szczecin, Department of Histology and Embryology, Powstańców Wlkp. 72, 70-111 Szczecin, Poland \\ ${ }^{3}$ Pomeranian Medical University in Szczecin, Department of Biochemistry and Medical Chemistry, Powstańców Wlkp. 72, 70-111 Szczecin, Poland \\ ${ }_{4}^{4}$ Pomeranian Medical University in Szczecin, Department of Dermatology and Vanereology, Siedlecka 2, $72-010$ Police, Poland \\ ${ }^{5}$ University of Szczecin, Faculty of Physical Culture and Health Promotion, Cukrowa 12, 71-004 Szczecin, Poland \\ A ORCID: 000-0003-4915-9875; $\quad{ }^{B}$ ORCID: 0000-0002-7392-7902; $\quad{ }^{C}$ ORCID: 0000-0001-9187-8895; $\quad$ D ORCID: 0000-0003-3855-7595; E ORCID: 0000-0002-9064-6969; \\ ORCID: 0000-0002-7551-1927

\begin{abstract}
Introduction: There is growing interest in the risk or benefits soybean food known as rich in isoflavones, due to their interactions with endogenous estrogen signal transduction pathway. Recent studies provide evidence that isoflavones can affect the reproductive and endocrine system under regular diet.

The aim of this study was to determine how the long-lasting administration of the key isoflavones, genistein and daidzein, may change morphology of the testis and the function of the epididymal antioxidant system of male rats.

Materials and methods: Male rats were treated by genistein and daidzein, in combination 2 (S2) or 20 (S20) mg/kg body weight per day for 5 days weekly mixed with regular rat chow from prenatal life until to sexual maturity. The control groups were fed without isoflavones.

Results: The findings show that the body, testis and cauda epididymis weights, testosterone level in blood plasma were
\end{abstract}

significantly lower than controls in the S20 group $(\mathrm{p}<0.05)$. Also, superoxide dismutase activity in the epididymis, catalase activity in the testis, and glutathione peroxidase activity in the caput epididymis were significantly decreased $(\mathrm{p}<0.05)$. Treating with these isoflavones significantly suppressed lipid peroxides levels in the epididymis $(\mathrm{p}<0.05)$. Furthermore, presence of prematurely exfoliated gametogenic cells was observed in seminiferous tubules as well as the architectural disorganization of the seminiferous epithelium.

Conclusions: These findings suggest that isoflavones, if consumed chronically at a dose as for the S20 group may act not only as antioxidants, but they can be a risk for the male rats reproductive system dysfunction.

Keywords: phytoestrogens; testis; epididymis; male; antioxidant; prooxidant.

\section{INTRODUCTION}

Over the last decade, growing evidence has been accumulated indicating the crucial role of oxidative stress (OS) in the pathogenesis of a number of diseases, including reproductive system diseases [1]. Spermatozoa cells are particularly susceptible to OS and lipid peroxidation due to their reduced cytoplasm content and the predominance of polyunsaturated fatty acids (PUFAs) in the plasma membrane [2, 3]. The cells of the male reproductive system are able to synthesize a complex of antioxidants, including highly specialized antioxidant enzymes and non-enzymatic antioxidants [1, 4]. Reactive oxygen species (ROS) that are formed at low to moderate level in the male reproductive system enable proper spermatogenesis, the formation of an adequate number of motile spermatozoa able to fertilize the egg, stimulate capacitation of the spermatozoa and the acrosome reaction [1, 2]. Accordingly, excessive ROS production and/or weakened ability of the cells to counteract or detoxify the reactive species or to repair the resulting damage (a state called OS), may affect the development and proper functioning of the male reproductive system in adulthood and can lead to male infertility [5].

The wide range of biological abilities of phytoestrogens have attracted increasing scientific interest over the past 2 decades as they may exert health benefits, particularly due to their antioxidant capability. Soy is the most significant source of genistein and daidzein, 2 key isoflavones whose chemical structure is similar to that of estradiol (17- $\beta$-estradiol - E2). These soy isoflavones (SI) can bind to an estrogen receptor $(E R \alpha)$, thus they have the potency to interact with estrogen or androgen signal transduction and are considered to be endocrine disruptors $[6,7]$. Isoflavones have been reported to exhibit anti-inflammatory, anticancer, and cardioprotective potential [8]. Conversely, they may cause also adverse effects on the male reproductive system $[9,10]$. For example, exposure of a developing testis during the "critical window of sensitivity" to phytoestrogens can disturb the process of spermatogenesis in adult life and reduce the amount of haploid germ cells in the testis, as well as cause a decrease in the 
sperm count in the epididymis in mice $[11,12]$. Although much of the research was carried out on the effect of phytoestrogens on the reproductive and endocrine systems, the evidence remains contradictory [13] due to differences in the type of isoflavones tested, the dosages and duration of supplementation. In addition, a limited number of studies have evaluated the positive and negative effects of daidzein and genistein on the male rat reproductive system.

In this study we hypothesized that long-lasting administration of isoflavones may change the morphology of the testes in male rats and the development and function of the epididymal antioxidant system. To this end we studied the influence of mixture of daidzein and genistein, administered to the rats from prenatal life until sexual maturity, on the morphology of the testis and epididymis, and on the activity of specific cellular antioxidant enzymes and concentrations of reduced glutathione (GSH) and lipid peroxides (LPO) in both organs.

\section{MATERIALS AND METHODS}

\section{Animals and study design}

Sexually mature 3-month-old female Wistar rats were kept for a week in a cage with sexually mature males (2:1) under standard lighting (12L:12D) and nutrition, then placed in individual cages. The pregnant females were randomly allocated to 3 groups of 4 per group: a control group on a normal diet (C), and 2 groups treated with daidzein and genistein at doses of: 2 $\mathrm{mg} / \mathrm{kg}$ b.w./day (S2 group) and $20 \mathrm{mg} / \mathrm{kg} \mathrm{b.w./day} \mathrm{(S20} \mathrm{group).}$ The selection of genistein and daidzein doses was based on their possible abundance in the human soy diet [14]. Rats had free access to food and water. Females of $\mathrm{S} 2$ and $\mathrm{S} 20$ groups received per os the daidzein and genistein mixture (Meno Stop - HASCO Lek, Poland) with rat chow from the feed store from the 1st day of experiment until delivery and during lactation. The SI mixture was given once a day (in the morning) for 5 days per week, individually to each rat in the form of pellet mixed with regular rat chow. The females of the control group received individually regular rat chow without SI. After separating rat pups from their mothers, young males of $\mathrm{S} 2$ and $\mathrm{S} 20$ groups ( $n=8$ /group) were continuously treated with the same doses of SI with rat chow until reaching the age of sexual maturity, i.e. for 3 months (groups S2 and S20) or fed without SI added (control group, C). After the period of treatment, the rats were sacrificed under thiopental anesthesia (120 mg-kg-1 b.w., i.p., Biochemie GmbH, Austria).

The experiments were conducted with the approval of the Local Ethical Committee (No. 33/2010).

\section{Determination of blood plasma hormones concentrations}

The clotted samples of blood were centrifuged, next the levels of testosterone (T) and E2 were measured in collected sera using an ECLIA-Electrochemiluminescence Immunoassay method (Cobas 6000 analyzer, Roche, Switzerland). The measurement range and precision of the T assay were $0.025^{-15} \mathrm{ng} / \mathrm{mL}$, $( \pm 0.1 \mathrm{ng} / \mathrm{mL})$, respectively. The measurement range and precision of the E2 assay were $5-4300 \mathrm{pg} / \mathrm{mL}( \pm 12 \mathrm{pg} / \mathrm{mL})$, respectively.

\section{Morphology and morphometry}

The animals and their testes and epididymides (separately caput and cauda) were weighted. The organs were fixed in Bouin's fluid and embedded in paraffin, then series of slides (3-5 $\mu \mathrm{m})$ were prepared. Slides were stained using the periodic acid-Schiff (PAS) method [14], the nuclei of cells were additionally stained with acid hematoxylin. Morphometric studies were performed on the slides used for morphological evaluation. All measurements (average of 100 measurements in each group) were made on randomly chosen animals. The diameter of seminiferous tubules at the shortest distance between 2 parallel tangent lines of the outer edge of the tubule was rated. In the epididymis, the diameter of whole cross section of ductus epididymis, the lumen of ductus epididymis and the height of the epithelium lining the ductus as the difference between the diameter of the entire cross-section of the ductus and the diameter of its lumen were rated. All measurements were performed at magnification $\times 20$ using the light microscope and Axio Vision Rel. 4.6 program (Zeiss, Axioscope, Germany) Figures 1 and 2.
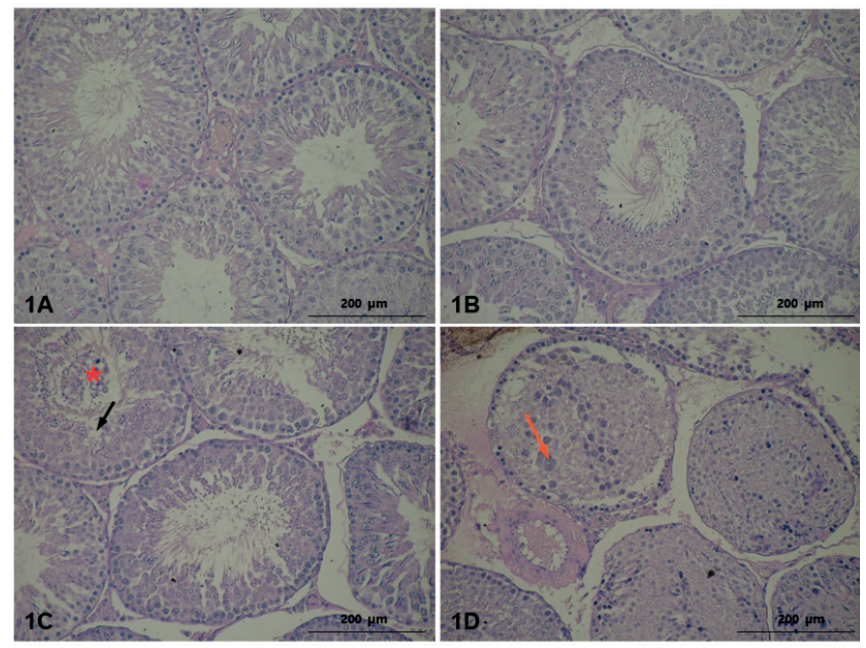

FIGURE 1. The morphology of the testis in: the control group (A), rats exposed to soy isoflavones at a dose of $2 \mathrm{mg} / \mathrm{kg}$ b.w. $/ \mathrm{d}$ (B); rats exposed to soya isoflavones at a dose of $20 \mathrm{mg} / \mathrm{kg}$ b.w./d (C and D). Periodic acid-Schiff; black arrow - empty space in the seminiferous epithelium as a consequence of prematurely sloughed germ cells; orange arrow multinucleated giant cell; red star - prematurely exfoliated germ cells

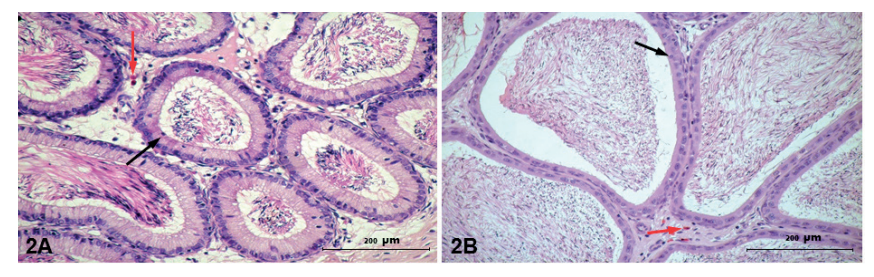

FIGURE 2. The morphology of the head (A) and the cauda (B) of epididymis in the control group. Periodic acid-Schiff; black arrows - intraepitelial lymphocytes; red arrows - mast cells in interstitial tissue 


\section{Biochemical evaluation}

Equal volumes of the testis and the caput and cauda epididymis ( $0.5 \mathrm{~g}$ ) were mixed with phosphate-buffered saline (PBS) buffer $(\mathrm{pH}=7.4)$, frozen in liquid nitrogen and underwent homogenization using a hammer mill. The suitable buffer volumes (5-10 mL/g tissue) were used for the specific analysis of a sample and added before shaking the tissues vigorously using a CAT X120 homogenizator (Germany). After contrifugation (12000 G, $10 \mathrm{~min}, 4^{\circ} \mathrm{C}$ ) supernatants were used to measure the activity of superoxide dismutase (SOD), catalase (CAT), glutathione peroxidase (GPx), glutathione reductase (GR) and concentrations of GSH and LPO, according to the attached instructions using suitable Assay Kits (Cayman Chemical Company, USA): Superoxide Dismutase Assay Kit, No. 706002, Catalase Assay Kit, No. 707002, Glutathione Peroxidase Assay Kit, No. 703102, Glutathione Reductase Assay Kit, No. 703202, Glutathione Assay Kit, No. 703002, and Lipid Hydroperoxide Assay Kit, No. 705002, respectively. Absorbance at suitable wavelength was measured with a plate reader Asys UVM 340 (Asys Hitech Gmbh, Austria).

Activities of antioxidant enzymes were converted into the total protein content using BCA Protein Assay Kit (Thermo Scientific Pierce, USA) according to the attached instructions, and absorbance at $562 \mathrm{~nm}$ was measured using a plate reader Asst UVM 340.

\section{Statistical analysis}

Data were analyzed using Statistica PL 6.1 software (Stat Soft Polska, Poland). The results are expressed as the mean \pm standard deviation (SD) - Tables 1 and 2 - or the mean \pm standard error (SE) of the mean (Tab. 3). For the study of the normality of the distribution variables the Shapiro-Wilk test was used. As most of the distributions were deviated from the normal Gauss distribution, in the comparison between 2 independent groups more often the non-parametric Mann-Whitney U test was used to find the significance of differences in means between treated and untreated with isoflavones groups. When the distribution of variability was normality, a Student's t-test was used in the analyses. For all statistical comparisons, a value of $\mathrm{p} \leq 0.05$ was considered statistically significant.

TABLE 1. Testosterone and estradiol concentrations in blood plasma of male rats exposed to soy isoflavones vs. the control groups

\begin{tabular}{lcc}
$\begin{array}{c}\text { Group/Dose } \\
\text { (mg/kg body } \\
\text { weight/day) }\end{array}$ & \multicolumn{2}{c}{$\begin{array}{c}\text { Blood plasma } \\
\mathrm{T}(\mathrm{ng} / \mathrm{mL}) \mathrm{E2}(\mathrm{pg} / \mathrm{mL})\end{array}$} \\
\hline Control (C) & $2.8 \pm 0.3$ & $35.00 \pm 3.30$ \\
\hline $\mathrm{S} 2$ & $2.7 \pm 0.4$ & $31.04 \pm 3.95$ \\
\hline $\mathrm{S} 20$ & $1.3 \pm 0.3^{*}$ & $30.88 \pm 3.52$
\end{tabular}

The values are mean \pm standard deviation, $n=8$ rats in each group. Star shows the level of significance: ${ }^{*} p<0.01$

TABLE 2. The body, testis, and epididymis weights of male rats exposed to soy isoflavones vs. the isoflavone free diet

\begin{tabular}{|c|c|c|c|c|}
\hline \multirow{2}{*}{$\begin{array}{l}\text { Group/Dose } \\
\text { (mg/kg body } \\
\text { weight/day) }\end{array}$} & \multirow{2}{*}{$\begin{array}{l}\text { Body weight } \\
\text { (g) }\end{array}$} & \multicolumn{3}{|c|}{ Testis and epididymis weight (g) } \\
\hline & & testis & $\begin{array}{c}\text { caput } \\
\text { epididymis }\end{array}$ & $\begin{array}{c}\text { cauda } \\
\text { epididymis }\end{array}$ \\
\hline Control (C) & $\begin{array}{l}360.00 \\
\pm 37.08\end{array}$ & $1.78 \pm 0.06$ & $0.29 \pm 0.19$ & $0.29 \pm 0.18$ \\
\hline $\mathrm{S} 2$ & $\begin{array}{l}328.00 \\
\pm 98.57\end{array}$ & $1.73 \pm 0.09$ & $0.29 \pm 0.28$ & $0.30 \pm 0.37$ \\
\hline S20 & $\begin{array}{c}312.50 \\
\pm 24.49 * *\end{array}$ & $\begin{array}{c}1.53 \\
\pm 0.14^{* * *} \text { \#\#\# }\end{array}$ & $0.27 \pm 0.19$ & $0.25 \pm 0.32 *$ \\
\hline
\end{tabular}

The values are mean \pm standard deviation ( $n=8$ rats in each group). Stars show the level of significance: ${ }^{*} p<0.05 ;{ }^{* *} p<0.01 ;{ }^{* * *} p<0.001$ vs. control groups; $\# p<0.01 ; \# \#<0.001$ vs. S2 groups.

TABLE 3. Effect of soy isoflavones on activities of enzymatic antioxidants and concentrations of glutathione and lipid peroxides in the testis and epididymis of male rats

\begin{tabular}{|c|c|c|c|c|c|c|}
\hline $\begin{array}{c}\text { Group/Dose } \\
\text { (mg/kg b.w./day) }\end{array}$ & $\begin{array}{c}\text { SOD } \\
\mathrm{U} / \mathrm{mg} \text { protein }\end{array}$ & $\begin{array}{c}\text { CAT } \\
\text { U/mg protein }\end{array}$ & $\begin{array}{c}\text { GPX } \\
\text { U/mg protein }\end{array}$ & $\begin{array}{c}\text { GR } \\
\mathrm{U} / \mathrm{mg} \text { protein }\end{array}$ & $\begin{array}{c}\text { GSH } \\
\mu \mathrm{M} / \mathrm{mg} \text { protein }\end{array}$ & $\begin{array}{c}\text { LPO } \\
\mu \mathrm{M} / \mathrm{mg} \text { protein }\end{array}$ \\
\hline \multicolumn{7}{|l|}{ Testis } \\
\hline Control (C) & $1.08 \pm 0.22$ & $596.19 \pm 51.71$ & $2.23 \pm 0.37$ & $10.06 \pm 4.99$ & $0.12 \pm 0.01$ & $8.75 \pm 1.89$ \\
\hline $\mathrm{S} 2$ & $1.08 \pm 0.22$ & $274.27 \pm 68.65^{\star}$ & $2.76 \pm 0.58$ & $4.97 \pm 0.66$ & $0.11 \pm 0.01$ & $4.42 \pm 0.59$ \\
\hline S20 & $1.41 \pm 0.38$ & $342.41 \pm 43.88^{*}$ & $2.88 \pm 0.39$ & $8.36 \pm 5.00$ & $0.28 \pm 0.02^{* *}$ & $4.92 \pm 0.45$ \\
\hline \multicolumn{7}{|l|}{ Caput epididymis } \\
\hline Control (C) & $3.24 \pm 0.45$ & $92.85 \pm 9.75$ & $2.19 \pm 0.37$ & $15.25 \pm 1.93$ & $0.15 \pm 0.15$ & $9.00 \pm 2.00$ \\
\hline S2 & $1.23 \pm 0.20^{*}$ & $131.26 \pm 39.90$ & $4.01 \pm 0.67$ & $3.87 \pm 1.02$ & $0.14 \pm 0.01$ & $6.51 \pm 0.51$ \\
\hline S20 & $0.89 \pm 0.15^{*}$ & $96.20 \pm 25.37$ & $6.91 \pm 1.72^{*}$ & $3.44 \pm 0.56^{*}$ & $0.12 \pm 0.02$ & $4.62 \pm 0.56^{*}$ \\
\hline \multicolumn{7}{|l|}{ Cauda epididymis } \\
\hline Control (C) & $6.02 \pm 0.83$ & $38.10 \pm 4.79$ & $7.56 \pm 1.14^{*}$ & $2.39 \pm 0.23$ & $0.07 \pm 0.02$ & $7.05 \pm 0.54$ \\
\hline S2 & $2.15 \pm 0.19 *$ & $31.85 \pm 3.40$ & $7.15 \pm 1.17$ & $8.86 \pm 2.76$ & $0.10 \pm 0.01$ & $5.02 \pm 0.23$ \\
\hline S20 & $1.53 \pm 0.27^{*}$ & $40.34 \pm 14.59$ & $7.26 \pm 2.94$ & $8.87 \pm 0.75^{* *}$ & $0.11 \pm 0.01$ & $3.08 \pm 0.21^{\text {*\# }}$ \\
\hline
\end{tabular}

SOD - superoxide dismutase; CAT - catalase; GPx - glutathione peroxidase; GR - glutathione reductase; GHS - glutathione; LPO - lipid peroxides

All the values are expressed as mean \pm standard error of the mean, $n=8$ rats in each group. Values denoted as * or ** are significantly different from each other at $p<0.05$ or $p<0.01$ vs. controls, respectively; ${ }^{*} p<0.05$ vs. S2 group. 


\section{RESULTS}

\section{Plasma concentrations of testosterone and estradiol}

The exposition of animals to SI at medium dose $(20 \mathrm{mg} / \mathrm{kg}$ b.w./d) significantly decreased the T level (by 46.4\%) in blood serum as compared to the control group. There were no significant differences in E2 concentrations in blood serum in the SI treated groups at a dose of $2 \mathrm{mg} / \mathrm{kg}$ b.w./d comparing to the control group (Tab. 1).

\section{Body, testis and epididymis weight}

Treatment of rats at $20 \mathrm{mg} / \mathrm{kg}$ b.w./d dose-level significantly decreased the body, testis and cauda epididymis weights of rats as compared to both the control groups and the groups treated with SI at dose $2 \mathrm{mg} / \mathrm{kg}$ b.w./d. In addition, the weight of the caput epididymis tended to decrease in the SI treated groups, but the differences were not statistically significant (Tab. 2).

\section{Morphological analysis}

\section{The testis}

The epithelium of the seminiferous tubules in rats of the control group revealed the presence of all generation of cells in spermatogenesis pathway, appropriate to the stage of the cycle of the seminiferous epithelium (Fig. 1A).

In the seminiferous tubules of rats exposed to SI at a dose of $2 \mathrm{mg} / \mathrm{kg}$ b.w./d no obvious morphological changes were observed. Occasionally, the presence of prematurely exfoliated germ cells in the lumen of the seminiferous tubules was noted (Fig. 1B). In contrast, in the seminiferous tubules of rats exposed to SI at a dose of $20 \mathrm{mg} / \mathrm{kg}$ b.w./d, the presence of prematurely exfoliated gametogenic cells in the lumen of the seminiferous tubules was observed in more numerous tubules compared to the $\mathrm{S} 2$ group. The presence of the empty space in the seminiferous epithelium as a consequence of sloughed cells was noted (Fig. 1C and 1D). In other tubules, the architectural disorganization of the seminiferous epithelium manifested by the presence of type I of spermatocytes in the central part of the tubule as well as the presence of multinucleated giant cells were found.

\section{The caput epididymis}

Figure 2 presents the morphology of the head and the cauda of epididymis. In the cross sections of the caput epididymis in the control group, the regular lumen lined with high epithelium and well developed stereocilia on the apical surface of principal cells as well as intraepithelial lymphocytes were observed within the epithelium (Fig. $2 \mathrm{~A}$ - red arrows). The duct was surrounded by 2-3 layers of smooth muscle cells. The loops of the ductus epididymis were supported by abundant interstitial tissue in which the mast cells were visible (black arrows). The morphological analysis of the caput epididymis did not show any significant changes neither in the epithelium, basal lamina nor in the smooth muscle cells surrounding the ductus epididymis in rats of both groups treated with SI (data not shown).

\section{The cauda epididymis}

In the cauda epididymis of the control animals, the lumen was irregular, the epithelium was lower than in the caput and the diameter of lumen was larger (Fig. 2B). Within the epithelium intraepithelial lymphocytes were shown (red arrows). Below the basal lamina, 3-4 layers of smooth muscle cells were visible. The loops of the ductus epididymis were supported by a small amount of the interstitial tissue, in which the mast cells were noted (black arrows).

There were no significant changes occurring in the epithelium, basal lamina nor underlying smooth muscle cells in the rats treated with SI at both doses compared with the control group (data not shown).

\section{Morphometry}

The testis of rats from the S20 group exhibited significant reduction in diameter $(\mu \mathrm{m})$ of the seminiferous tubules compared to the control group as well as compared to the S2 group (means \pm SD: $=270.99 \pm 21.85,299.85 \pm 40.40,296.47$ \pm 43.89 , respectively; $p<0.001$ ). No significant changes in the tested parameters in S2 group as compared to the control group were seen. The differences in the diameter of caput and cauda epididymis duct, the diameter of the lumen and the height of the epithelium in the soya-treated rats were not statistically significant (data not shown).

\section{Superoxide dismutase, catalase, glutathione peroxidase, and reductase activities}

Regarding the effects of rats treatment with SI on the OS status in the testis, caput and cauda epididymis homogenates we observed a significant decrease of SOD activity in the caput and the cauda epididymis in both the treated groups of rats S2, S20 (caput $62 \%$ and $72 \%$; cauda $64 \%$ and $74 \%$, respectively), as compared to the control group ( $\mathrm{p}<0.05)$ - Table 3 .

Further, the CAT activity was significantly decreased in the testis of both the treated groups S2 (54\%) and S20 $(42 \%)$ compared to the control group $(\mathrm{p}<0.05)$ and it was unchanged in the epididymis. Treatment with SI had no significant effect on the GPx activity in both the testis and in the cauda epididymis in S2 group. However, the GPx activity in S20 group rats after treatment with SI was significantly increased by 3.15 times in the caput epididymis, compared with the untreated rats. Further, the GPx activity in the cauda of epididymis of untreated rats was 3.45 times higher than in the caput epididymis of the control group. The GR activity in the caput epididymis homogenate of S20 group was significantly decreased by 4.44 times $(\mathrm{p}<0.05)$, while the enzyme activity in the cauda epididymis homogenate was increased by 3.71 times ( $p<0.01)$, compared with the respective control groups.

\section{Glutathione and lipid peroxides concentrations}

In the testis of $\mathrm{S} 20$ group concentration of GSH was significantly increased by approx. 2.3 times compared to the control group. In both the groups (S2, S20), the concentrations of LPO were decreased compared with the control group. The decrease reached significant levels and was a dose - dependent for the 
caput and cauda epididymis in the S20 group. The concentration of LPO in the cauda epididymis homogenates in the S20 group was significantly lower by 2.29 times vs. the control group and it was lower by 1.63 times vs. S2 group.

\section{DISCUSSION}

The current study was carried out to investigate the antioxidant/prooxidant effects of soy derived isoflavones daidzein and genistein on the male testis and epididymis. As we noted the rats's supplementation with SI at lower dose (S2 group) had no effect on T level in blood serum, which is consistent with the previous findings [15]. In contrast, a significant decrease of the T level occurred in blood serum of rats exposed to dose of $20 \mathrm{mg} / \mathrm{kg}$ b.w./d. This result may corroborate the finding of Napier et al. in male rats treated with a high dose of the genistein and daidzein mixture during prenatal life and lactation [16]. The authors stated that daidzein and genistein stimulated proliferative activity in developing Leydig cells but suppressed their steroidogenic activity in adulthood. Phytoestrogens were also found to inhibit proliferation of Leydig cells in rats whose mothers were exposed to SI during pregnancy and lactation $[17,18]$. In addition, in vitro study concerning the influence of genistein on Leydig, Sertoli, and germ cells in the male gonad showed that the compound inhibited the growth and proliferation of all 3 types of cells and that the germ and Leydig cells were the most sensitive to genistein [19]. Besides, it was demonstrated that substances that exhibit a low estrogen activity like phytoestrogens may cause cryptorchidism, epididymal cysts, residual remnants of Müllers' ducts, changes in the function of Sertoli and Leydig cells, decrease testis weight and germ cells number, alterations in the seminiferous tubules as well as increase in number of apoptotic germ cells in the prenatal period, depending on their dose and time of exposure [20]. Reduced plasma T level also was found in rats treated with a high dose of phytoestrogens for approx. 5 weeks [21]. The authors observed nonsignificant differences in plasma E2 levels between the phytoestrogens treated group and the control group, as was observed in our study. While some reports found no $\mathrm{T}$ changes in male rats treated with genistein [19]. These findings indicate that genistein administered alone does not exhibit as strong effect as given together with daidzein. Interestingly enough, the synergy effect of daidzein and genistein on the reproductive system of male mice was actually confirmed [22]. At a very early stage of the reproductive system development when the blood-testis and bloodepididymis barriers are not fully developed, the system is very sensitive even to gentle alterations in the microenvironmental conditions, what may cause serious consequences in adult life. A study of young men exposed to genistein, daidzein and glycitein (40 mg/kg b.w./d) for 2 months did not find a significant imbalance in blood serum concentration of $\mathrm{T}[11,23]$. This finding also shows that adult period of life is not as susceptible to biochemical alterations as prenatal period. Moreover, rats have ability to metabolize daidzein to equol, whereas only $30-50 \%$ of people have intestinal bacteria producing equol [24].

Our study revealed a significant decrease in the weight of body, testis and cauda epididymis in the S20 group vs. both the $\mathrm{S} 2$ group and the control group. The decrease in the body weight of rats treated with phytoestrogens has been also noted by other authors, however the authors used a high isoflavones dose (300 mg/kg b.w./d) [21]. In turn, Faqi et al. found that sexually mature rats chronically ( 12 months) administered with SI mixture at doses of 200 and $2000 \mathrm{mg} / \mathrm{kg} \mathrm{b.w./d} \mathrm{had} \mathrm{an}$ unchanged weight of the body, testis, and epididymis [25]. These findings indicate that time of exposition or "the critical time of sensitivity" rather than the dose of SI are the key parameters.

In the testis of the S20 group our results showed disorders in the morphology of the seminiferous epithelium, i.e. the presence of empty spaces after prematurely exfoliated germ cells into the lumen of seminiferous tubules. This finding may be a consequence of a hormonal imbalance, which may result from the decreased level of circulating $\mathrm{T}$ [26]. The presence of polynuclear giant cells within some seminiferous tubules was observed. These cells are formed from spermatogenic cell which have lost the connection with Sertoli cells [27]. The results suggest that formation of this type cells may be a result of a severe apoptosis of germ cells. Evidence indicates that SI are involved in a number of functions at the molecular level $[8,12]$ and they regulate the cell cycle and apoptosis $[28,29]$. In the contrary to the testis, we did not reveal any histological abnormalities of the caput epididymis nor cauda epididymis in both the SI treated groups. This observation is similar to findings of other researchers $[11,26,30]$ and may result from a high stability of epithelial cells in the ductus epididymis (a poorly renewing population), which is characterized by a low mitotic index [31].

A more detailed evaluation of the testis and the epididymis originates from the morphometric analysis. Our study and those of Cederroth et al. [11] and Eustache et al. [15] found significant reductions in the diameter of the seminiferous tubules in the testis of both the SI treated rats, but not in the epididymis.

There is growing evidence of the involvement of ROS alone and their intermediates in the pathogenesis of the male reproductive system injury $[32,33]$. The present study adds to recent evidence that the SI supplementation can exert the positive effect on redox homeostasis in the testis and the epididymis.

In the male reproductive system, the most sensitive to oxidative damage are cell membranes of spermatozoa which are rich in PUFAs [34]. The present data demonstrate no statistically significant decrease in LPO concentration in the testis but significantly decreased LPO levels in the epididymis of S20 group. This finding means that the mixture of daidzein and genistein in addition to their estrogenic actions possesses antioxidant effect in the cauda epididymis. Isoflavones can scavenge products of lipid per oxidation acting as the hydrogen atom donor, thus they can stop free radical chain reactions [35]. However, in a study of Swiss mice, increased LPO level after a single injection of genistein at high doses was found in the 
liver [36]. This discrepancy may be due to the high dose of genistein and type of target tissue. In addition, the antioxidant effectiveness of genistein alone may be less than that in combination with daidzein.

During epididymal transit, spermatozoa are exposed to various types of ROS, which are by-products of the cellular metabolism. Too high level of ROS may cause lipid peroxidation of the sperm plasma membrane, affect membrane fluidity, decrease fertilizing capacity, and even cause the sperm necrosis [37]. Evidence exist that SI may induce the expression of several antioxidant enzymes [38]. Superoxide dismutase is involved in removing superoxide anion radical $\left(\mathrm{O}_{2}^{\overline{2}}\right)$ of which concentration increases, e.g. during the maturation of spermatozoa [4] In the current study we found that SOD activity in the caput and cauda epididymis of rats exposed to SI was significantly lower compared to the controls. This finding is not entirely unexpected, as SI have been reported to act as ROS scavengers among other their activities (e.g. estrogenic, tyrosine kinase inhibiting) $[4,7,12]$. However, our observation is not in line with the study of Abarikwu et al. who did not reveal changes in SOD activity in the epididymis of sexually mature male rats treated with rutin [39]. It is possible that rutin might exhibit lower antioxidant activity than the mixture of genistein and daidzein. In addition, rutin was administered only 2ce a week for a month, in contrast to the chronic treatment in our experiment.

To obtain more inside into the biological significance of administration of SI on testis and epididymis, the activities of CAT, GPx, and GR were evaluated. All the 3 enzymes are known to protect the cell from oxidative damage by free radicals and nonradical $\mathrm{ROS}$ ( $\mathrm{H}_{2} \mathrm{O} 2$ and singlet oxygen) $[4,40]$.

The current data also revealed a significant reduction of CAT activity in the rats testis of both the SI-treated groups and a lack of such relationships for the caput and cauda of the epididymis, as compared to the control groups. These findings may be compared with the data of 2 previous studies [39, 41]. The study by Abarikwu et al. reported unchanged activities of SOD, CAT, GPx, and GR in testis and epididymis of male rats which were treated with rutin $(30 \mathrm{mg} / \mathrm{kg})$ twice a week for 4 weeks, presenting findings partly compatibility with our results [39]. The 2nd study by Barbosa et al. examined the effect of ingestion of aglycone isoflavone $(5 \mathrm{mg} / \mathrm{kg} / \mathrm{day}$ ) for 30 days in male rats reporting increased antioxidant activities of blood plasma, SOD and GPx in erythrocytes, and also in the kidney and liver tissues, although CAT activity was increased in erythrocytes but decreased in blood plasma, in contrast to our observation [41]. Thus, one might have expected that SI can affect the activity of the same antioxidant enzyme in different ways, depending not only on their dose but also on the isoflavones type chosen in these experiments, or the target tissue type. These results show the specificity of CAT action, which is known as an effective antioxidant when the level of $\mathrm{H} 2 \mathrm{O} 2$ is very high $[4,36]$. Under our experimental conditions, when SOD activity was reduced in the epididymis after treatment with SI and the enzyme did not generate large amounts of $\mathrm{H}_{2} \mathrm{O} 2$, the finding that CAT level was not changed seems to be reasonable.
In the S20 group there was significant increase in the GPx activity in the caput epididymis eliminating difference between the enzyme activity in the caput epididymis and the cauda epididymis that observed between the control groups. This result cannot be directly compared with previous ones. For example, Park et al. noted significantly increased level of GPx protein in the epididymal spermatozoa as the progress by successive portions of the epididymis [37]. This finding demonstrates the heterogeneous demand of spermatoza for GPX during thier transit through the epididymis.

To the best of our knowledge, the current study is the 1st that investigated the effect of SI on the GR activity in epididymis. We found a statistically significant reduction in GR activity in the caput epididymis and its increase in the cauda epididymis in the S20 group compared with the controls. This result for the cauda epididymis corresponds with the body of evidence available from published literature that phytoestrogens can reduce the level of OS in tissues directly acting as proton donors as well as indirectly, e.g. by an increase in levels of antioxidant enzymes or by transcriptional activation of various antioxidant genes $[12,42]$. In fact, evidence exists that genistein and daidzein exhibit a high reactivity towards, $\mathrm{H}_{2} \mathrm{O}_{2}$, in vitro [43]. On the other hand, the isoflavones as phenolic compounds can be oxidized to quinones followed by generation of free radicals being toxic for cell at higher concentrations [12]. Our finding that the activity of GR varied depending on the epididymis region allows to suggest that GR is a tissue-specific enzyme. These changes are likely due to the physiological, morphological and biochemical differences that occur in subsequent sections of this organ [44].

This study found significant increase in GSH concentration in the testis of the S20 group, which is in contrast with previous finding by Abarikwu et al. [39]. Results for the caput epididymis and cauda epididymis in the SI treated rats revealed a lack of differences in the GSH concentration among the examined groups. In this case our findings are in agreement with a study of Abarikwu et al. [39]. The observed increase in GSH level in the testis of S20 group may suggest that SI play an important role in scavenging ROS under our low OS conditions. The effect of SI consumption on reproductive systems has been mainly evaluated in animal models and in a small number of human studies. Evidence has recognized that animal data are often consistent with findings in humans [15]. The current state of evidence regarding the effect of environmental estrogens on humans and animals' health includes the classical genomic pathway (receptor activation and gene transcription) and nongenomic pathways, i.e. by rapid membrane effects mediated, e.g. by OS pathways, tyrosine kinases, and nuclear transcription factor - NF- $\kappa \beta$. Both the estrogenic and anti-estrogenic effects of genistein and daidzein are linked with their polyphenolic structures similar to that of E2, i.e. abilities to interact with ER $\alpha$ and $\operatorname{ER} \beta$ [45]. The isoflavones can exert their effects in the hypothalamic-pituitary-gonadal axis of the endocrine system by modulating production and secretion of the gonadotropin hormones: luteinizing hormone and follicle stimulating hormone. Luteinizing hormone stimulates sex 
steroid production including E2 and testosterone and controls spermatozoa formation in males.

\section{CONCLUSIONS}

Summing up, our results provide additional evidence that chronic administration of daidzein and genistein in combination to male rats from fetal life until to sexual maturity may result in positive effect on maintaining redox balance in the epididymis. The protective effect of these isoflavones on male reproductive system is confirmed in the $\mathrm{S} 20$ group as where isoflavone intake was inversely related to the LPO concentration in the epididymis and positively correlated to the GPx activity in the caput epididymis and to the GSH concentration in the testis. However, the observed decreases in the SOD activity in the epididymis and the CAT activity in the testis show the weakness the cellular antioxidant defense. In addition, the decreases in the weights of the testis and the cauda epididymis and serum $\mathrm{T}$ level as well as the testicular lesion in the seminiferous tubules and the architectural disorganization of the seminiferous epithelium imply that chronic administration of SI at $20 \mathrm{mg} / \mathrm{kg} \mathrm{b.w./d} \mathrm{dose} \mathrm{has} \mathrm{the} \mathrm{potential} \mathrm{to} \mathrm{affect}$ androgen deficiency. Our novel finding is an observation that the GR activity was dependent on the region of the epididymis being significantly decreased in the caput and increased in the cauda epididymis in the S20 group.

Future research should determine the level of evidence for factors that remain in the subject literature conflicting, such as type and optimal SI dose, the additive or synergic action of their mixture, optimal duration of SI exposition and a window of opportunity for treatment among other, which are not identified yet. This may allow to maintain the cellular redox homeostasis in the male reproductive system. Also, additional experimental and epidemiological studies are required to expand current knowledge dealing with the synergic or additive effects of genistein and daidzein on male sexual organs.

\section{REFERENCES}

1. Aitken RJ, Smith TB, Jobling MS, Baker MA, De Iuliis GN. Oxidative stress and male reproductive health. Asian J Androl 2014;16(1):31-8.

2. Aitken RJ, De Iuliis GN. On the possible origins of DNA damage in human spermatozoa. Mol Hum Reprod 2010;16(1):3-13.

3. Hermo L, Pelletier RM, Cyr DG, Smith CE. Surfing the wave, cycle, life history, and genes/proteins expressed by testicular germ cells. Part 1: background to spermatogenesis, spermatogonia, and spermatocytes. Microsc Res Tech 2010;73(4):241-78.

4. Ko EY, Sabanehg ES Jr, Agarwal A. Male infertility testing: reactive oxygen species and antioxidant capacity. Fertil Steril 2014;102(6):1518-27.

5. Walczak-Jędrzejowska R. Stres oksydacyjny a niepłodność męska. Część I: czynniki wywołujące stres oksydacyjny w nasieniu. Post Androl Online 2015;2(1):5-15.

6. Sharpe RM, Irvine DS. How strong is the evidence of a link between environmental chemicals and adverse effects on human reproductive health? BMJ 2004;328(7437):447-51

7. Cederroth CR, Zimmermann C, Nef S. Soy, phytoestrogens and their impact on reproductive health. Mol Cell Endocrinol 2012;355(2):192-200.
8. Smoliga JM, Baur JA, Hausenblas HA. Resveratrol and health - a comprehensive review of human clinical trials. Mol Nutr Food Res 2011;55(8):1129-41.

9. Sharpe RM, Skakkebaek NE. Are oestrogens involved in falling sperm counts and disorders of the male reproductive tract? Lancet 1993;341(8857):1392-5.

10. Caceres S, Silvan G, Martinez-Fernandez L, Illera MJ, Millan P, Monsalve $B$, et al. The effects of isoflavones on androgens and glucocorticoids during puberty on male Wistar rats. Reprod Domest Anim 2014;49(4):611-7.

11. Cederroth CR, Auger J, Zimmermann C, Eustache F, Nef S. Soy, phytooestrogens and male reproductive function: a review. Int J Androl 2010;33(2):304-16.

12. Sirotkin AV, Harrath AH. Phytoestrogens and their effects. Eur J Pharmacol 2014;741:230-6

13. Li L, Chen X, Luo Q, Huang C, Liu W, Chen Z. Effects of soy isoflavones on testosterone synthetase in diet-induced obesity male rats. Int J Clin Exp Pathol 2017;10(9):9202-12.

14. Agarwal A, Sekhon LH. The role of antioxidant therapy in the treatment of male infertility. Hum Fertil (Camb) 2010;13(4):217-25.

15. Eustache F, Mondon F, Canivenc-Lavier MC, Lesaffre C, Fulla Y, Berges R, et al. Chronic dietary exposure to a low-dose mixture of genistein and vinclozolin modifies the reproductive axis, testis transcriptome, and fertility. Environ Health Perspect 2009;117(8):1272-9.

16. Napier ID, Simon L, Perry D, Cooke PS, Stocco DM, Sepehr E, et al. Testicular development in male rats is sensitive to a soy-based diet in the neonatal period. Biol Reprod 2014;90(2):40. doi: 10.1095/biolreprod.113.113787.

17. Lazari MFM, Lucas TFG, Yasuhara F, Gomes GRO, Siu ER, Royer C, et al. Estrogen receptors and function in the male reproductive system. Arq Bras Endocrinol Metab 2009;53(8):923-33.

18. Sherrill JD, Sparks M, Dennis J, Mansour M, Kemppainen BW, Bartol FF, et al. Develompental exposures of male rats to soy isoflavones impact Leydig cell differentiation. Biol Reprod 2010;83(3):488-501.

19. Carreau S, Hess RA. Oestrogens and spermatogenesis. Philos Trans R Soc Lond B Biol Sci 2010;365(1546):1517-35.

20. McLachlan JA. Environmental signaling: what embryos and evolution teach us about endocrine disrupting chemicals. Endocr Rev 2001;22(3):319-41.

21. Weber KS, Setchell KDR, Stocco DM, Lephart ED. Dietary soy-phytoestrogens decrease testosterone levels and prostate weight without altering $\mathrm{LH}$, prostate $5 \alpha$-reductase or testicular steroidogenic acute regulatory peptide levels in adult male Sprague-Dawley rats. J Endocrinol 2001;170(3):591-9.

22. Eumkeb G, Tanphonkrang S, Sirichaiwetchakoon K, Hengpratom T, Naknarong $\mathrm{W}$. The synergy effect of daidzein and genistein isolated from Butea superba Roxb. on the reproductive system of male mice. Nat Prod Res 2017;31(6):672-5.

23. Mitchell JH, Cawood EW, Kinniburgh D, Provan A, Collins AR, Irvine DS. Effect of a phytoestrogen food supplement on reproductive health in normal males. Clin Sci (Lond) 2001;100(6):613-8.

24. Doerge DR. Bioavailability of soy isoflavones through placental/lactational transfer and soy food. Toxicol Appl Pharmacol 2011;254(2):145-7.

25. Faqi AS, Johnson WD, Morrissey RL, McCormick DL. Reproductive toxicity assessment of chronic dietary exposure to soy isoflavones in male rats. Reprod Toxicol 2004;18(4):605-11.

26. Piotrowska K, Baranowska-Bosiacka I, Marchlewicz M, Gutowska I, Noceń I, Zawiślak M, et al. Changes in male reproductive system and mineral metabolism induced by soy isoflavones administrated to rats from prenatal life until sexual maturity. Nutrition 2011;27(3):372-9.

27. Neumann F, Schenck B. Formal genesis of giant cells in the germinal epithelium in the rat thioglucose model. Andrologia 1997;9(4):323-8.

28. Hwang KA, Kang NH, Yi BR, Lee HR, Park MA, Choi KC. Genistein, a soy phytoestrogen, prevents the growth of BG-1 ovarian cancer cells induced by $17 \beta$-estradiol or bisphenol A via the inhibition of cell cycle progression. Int J Oncol 2013;42(2):733-40.

29. Prietsch RF, Monte LG, da Silva FA, Beira FT, Del Pino FA, Campos VF, et al. Genistein induces apoptosis and autophagy in human breast MCF-7 cells by modulating the expression of proapoptotic factors and oxidative stress enzymes. Mol Cell Biochem 2014;390(1-2):235-42.

30. Brown NM, Lindley SLL, Witte DP, Setchell KDR. Impact of perinatal exposure to equol enantiomers on reproductive development in rodents. Reprod Toxicol 2011;32(1):33-42

31. Kolasa A, Marchlewicz M, Świder M, Sikorski A, Wenda-Różewicka L, Wiszniewska B. Najądrze. In: Piasecka M, editor. Układ płciowy męski. 
Badania kliniczne i doświadczalne. Szczecin: Wydawnictwo Pomorskiego Uniwersytetu Medycznego w Szczecinie; 2013. p. 419-31.

32. Agarwal A, Virk G, Ong C, du Plessis SS. Effect of oxidative stress on male reproduction. World J Mens Health 2014;32(1):1-17.

33. Azenabor A, Ekun AO, Akinloye 0. Impact of inflammation on male reproductive tract. J Reprod Infertil 2015;16(3):123-9.

34. Nikolopoulou M, Soucek DA, Vary JV. Changes in the lipid content of boar sperm plasma membranes during epididymal maturation. Biochim Biophys Acta 1985;815(3):486-98.

35. Quideau S, Deffieux D, Douat-Casassus C, Pouységu L. Plant polyphenols: chemical properties biological activities, and synthesis. Angew Chem Int Ed Engl 2011;50(3):586-621.

36. Singh P, Sharma S, Rath SK. Genistein induces deleterious effects during its acute exposure in Swiss mice. Biomed Res Int 2014;2014:619617. doi: 10.1155/2014/619617.

37. Park K, Jeon S, Song YJ, Yi LSH. Proteomic analysis of boar spermatozoa and quantity changes of superoxide dismutase 1 , glutathione peroxidase, and peroxiredoxin 5 during epididymal maturation. Anim Reprod Sci 2012;135(1-4):53-61.

38. Mahmoud AM, Yang W, Bosland MC. Soy isoflavones and prostate cancer: a review of molecular mechanism. J Steroid Biochem Mol Biol 2014;140:116-32.
39. Abarikwu So, Otuechere CA, Ekor M, Monwuba K, Osobu D. Rutin ameliorates cyclophosphamide-induced reproductive toxicity in male rats. Toxicol Int 2012;19(2):207-14.

40. Bouayed J, Bohn T. Exogenous antioxidants - Double-edged swords in cellular redox state: Health beneficial effects at physiologic doses versus deleterious effects at high doses. Oxid Med Cell Longev 2010;3(4):228-37.

41. Barbosa AC, Lajolo FM, Genovese MI. Effect of free or protein-associated soy isoflavones on the antioxidant status in rats. J Sci Food Agric 2011;91(4):721-31.

42. Borrás C, Gambini J, Gómez-Cabrera MC, Sastre J, Pallardó FV, Mann GE, et al. Genistein, a soy isoflavone, up-regulates expression of antioxidant genes: involvement of estrogen receptors, ERK1/2, and NFKB. FASEB J 2006;20(12):2136-8.

43. Kładna A, Berczyński P, Kruk I, Piechowska T, Aboul-Enein HY. Studies on the antioxidant properties of some phytoestrogens. Luminescence 2016;31(6):1201-6.

44. Bedford JM. The epididymis re-visited: a personal view. Asian J Androl 2015;17(5):693-8.

45. Zhao E, Mu Q. Phytoestrogen biological actions on Mammalian reproductive system and cancer growth. Sci Pharm 2011;79(1):1-20. 